\title{
Assessment of light intensity and productivity in the intelligent building - case study
}

\author{
Anita Białek ${ }^{1}$, Luiza Dębska ${ }^{1 *}$, Natalia Krawczyk ${ }^{1}$ \\ ${ }^{1}$ Faculty of Environmental, Geomatic and Energy Engineering, Kielce University of Technology, 25-314 Kielce, Poland
}

\begin{abstract}
The paper focuses on important elements i.e. appropriate lighting conditions at workstations and the assessment of subjective productivity as a function of indoor environmental parameters, using the example of students in the intelligent building "Energis" at the Kielce University of Technology, where an experimental study was performed. A group of volunteers completed questionnaires about their subjective feelings related to lighting conditions in lecture halls at different times of the year and assessed their current productivity. Accurate physical measurements of illuminance with a high accuracy microclimate meter were carried out. Comparing the statements of the room users with the measurements allowed conclusions to be drawn about the conditions provided in the intelligent building related to lighting, as well as the impact of the working environment on the productivity of the room users. The findings provide valued information on lighting conditions in modern, intelligent buildings, which are becoming increasingly common around the world, for various purposes such as office, educational and other public buildings, so that appropriate indoor conditions can be used to optimise productivity and efficiency.
\end{abstract}

\section{Introduction}

Anyone staying in an enclosed space pays attention to the temperature inside, the quality of lighting, or even the lack of sufficient oxygen. Currently, a very fashionable trend is a state in which the thermal comfort in buildings is satisfactory and in accordance with the expectations of people staying in them. This is especially important in workplaces. As we know, when it is too hot, we feel tired and this affects our productivity. When it is too dark or the lighting is too bright, we strain our eyesight. This has a negative effect on our eyesight as well as on our work efficiency. It also negatively influences the number of mistakes we make and increases the risk of work accidents [1]. Employers creating new workplaces benefit from the knowledge of experienced engineers in order to provide better and better conditions in the facilities. Engineers using energy models, for specific types of buildings, are able to prepare and adapt the space to their needs. So that staff members feel comfortable in their workplaces. Intelligent buildings use modern ventilation systems, heat recovery, lighting control, cooling and heating in such a way that the economic effect is maximized and operating costs minimized.

When considering the impact of lighting on productivity, it is important to start with room-specific guidelines. These are contained in standard EN 12464. The exact requirements for the level and uniformity of illumination of the visual task area depending on the room in which the person resides and what work he performs. Therefore, the lighting requirements of a worker in a production hall are different from those of an office worker. According to the regulations, light intensity is measured in $[\mathrm{lx}]$ and the range of correct illumination is from 200 to 1500 [lx]. The required illumination values for educational rooms: classrooms $300[\mathrm{~lx}]$, meeting rooms and conference rooms - 500 [lx], reading rooms - $500[1 \mathrm{x}][2]$.

The literature extensively discusses studies of light intensity in the workplace conducive or not to employee satisfaction. Idkhan and Baharuddin [3] made a research on a group of 60 students doing internship in the laboratory of the Faculty of Mechanical Engineering. The goal of the investigation was to find out the thermal sensations of the subjects and the effect of light intensity on the work completed by the students at specified times. The methodology that the authors used in this study were questionnaires, an illuminance meter and a digital thermometer. The results showed that thermal comfort was achieved at $30.44^{\circ} \mathrm{C}$ and the illuminance value was 422.14 [lx]. Conclusions showed that the obtained parameters vary from the normal range, which may result in a decrease in work efficiency.

In the other case study developed by Bellia et al. [4] was presented to see if factors such as light and colour could affect the work performance of the occupants. Hence, the authors tested two kinds of lighting, warm $(3.000 \mathrm{~K})$ and cool $(6.000 \mathrm{~K})$ in an air-conditioned room for 163 people, where the illuminance value was 300 [lx] for temperatures of $20^{\circ} \mathrm{C}$ and $25^{\circ} \mathrm{C}$, with people feeling more comfortable with warm lighting. Furthermore, Kussmaul, Peri \& Boyd [5] conducted another study in elderly care facilities in New Zealand,

* Corresponding author: 1debska@tu.kielce.pl 
primarily considering the influence of internal factors on employees' perception of thermal discomfort or impairment of health or concentration, which may have a negative impact on quality of work. The authors' study examined whether environmental parameters such as temperature, humidity, noise and lighting met standards for work performed in nurses' offices and residents' waiting rooms. Measurements were taken continuously for 24 hours in nurses' offices and 12 hours in residents' waiting rooms. The results showed that temperature and light intensity did not meet the current standards, while noise and humidity were within the range of applicable international standards.

Thousands of studies and surveys have been produced examining indoor thermal comfort. An impressive example is the study conducted by Lipczynska et al. [6] on performance and efficiency. The study consisted of testing under three temperature conditions: $23^{\circ} \mathrm{C}, 26^{\circ} \mathrm{C}$ and $27^{\circ} \mathrm{C}$. Among the participants in the study, there were 14 people who suffered drowsiness at the highest air temperature. The study used a scale from "unproductive" to "very productive". It was found that the subjects' productivity increased as the thermal conditions improved. The more comfortable they felt, the more focused they were. In the following articles, we can see the correlation between room parameters and performance. For example: Akimoto et al. [7] conducted a study in which they contrasted thermal comfort with work efficiency. The coauthors tested characteristics such as air temperature, radiant temperature, air velocity, and relative humidity. The results of the study on fatigue-perception showed that the study participants mostly felt drowsy and this was mainly dependent on the type of work being performed. The research author confirms that thermal comfort parameters affect room users. Yingdong et al. [8] also obtained similar results. They confirmed that human productivity is greater when neutral conditions prevail in the building. They made a comparison between the productivity of participants in rooms with and without fans. What they found was that work productivity was worse in rooms without fans. The authors [9] conducted a study on productivity in office buildings in which they collected 9794 questionnaires. It was observed that working time, proximity to windows, and the orientation of the workstation had the greatest impact on productivity decline. The nearer the window is to the employee's workstation, the better and more positive the impact on work efficiency.

Currently, there is a growing interest in lighting systems that not only provide adequate lighting conditions, but also reasonably low energy consumption. Therefore, lighting should be treated not as a nuisance, but as a resource. The impact and interdependence between systems is being analysed more and more. The article presents the results of research and surveys in order to discuss the impact of light intensity on the productivity of people working in intelligent buildings and to assess the light intensity by the respondents. The research topic undertaken is so interesting, necessary and up-to-date due to the evergrowing awareness of people resulting from the amount of time they spend in closed rooms. Previous studies have not provided information whether intelligent buildings can positively or negatively affect productivity or well-being. The research presented by the authors is primarily intended to provide new information about the quality of lighting, temperature control and carbon dioxide in the building under study, so that in the future, designers of modern buildings can better contribute to increasing people's well-being.

\section{Materials and methods}

The intelligent "Energis" building, which is an integral part of Kielce University of Technology was analysed. The building was built in 2012. It includes renewable energy sources such as photovoltaic cells, a wind turbine located on the roof of the building, solar panels, heat pumps. Moreover, the building is close to the passive building standard due to proper thermal insulation [10]. The nature of an intelligent building is given by the building management system (BMS), which controls lighting or temperature in rooms, ventilation, etc. Inside the building there are 22 classrooms and employees' offices and laboratories for conducting research. Energis is shown in Figure 1.

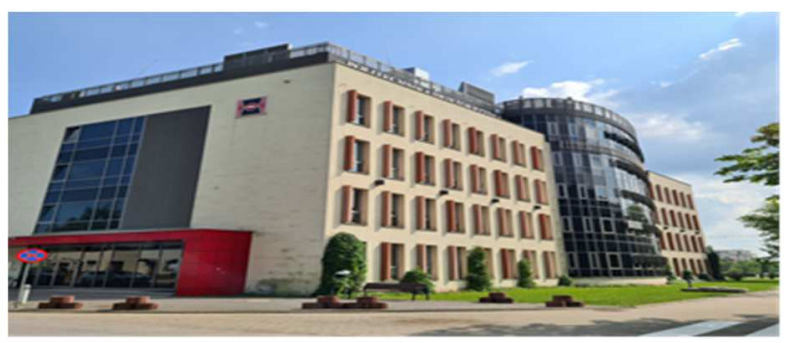

Fig. 1. A didactic building, part of the Kielce University of Technology, called 'Energis'.

The research was carried out in various classrooms with a cubature of $183 \mathrm{~m}^{3}$ to $1377 \mathrm{~m}^{3}$. The windows, depending on the rooms, were located to the east, south and west. In order to obtain the actual parameters in the rooms, the Testo 400 meter was used. On the other hand, people staying in the classrooms during the study completed the questionnaires in which they described the quality of lighting intensity, the level of their productivity and assessed their general well-being in each room. It should be added that the meter also measures air velocity, relative humidity and air temperature. Figures 2 and 3 show the probes for measuring the light intensity (yellow colour) and the height of carbon dioxide (green colour).

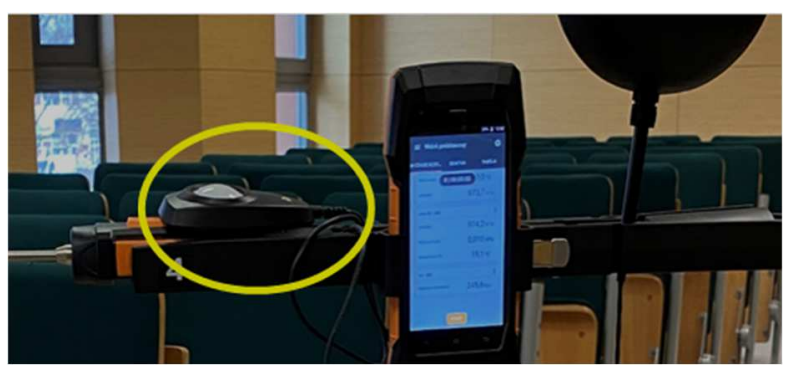

Fig. 2. Light intensity probe. 


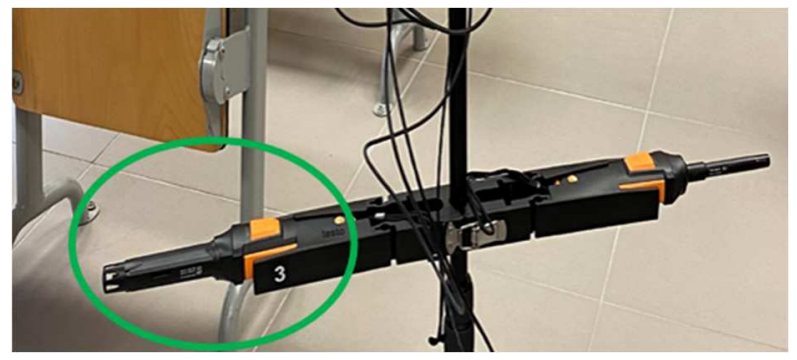

Fig. 3. Probe to collect information about the amount of $\mathrm{CO} 2$.

In order to undertake the research problem, a questionnaire was created in which the respondents presented their subjective feelings from 13 rooms. The study was carried out while the respondents were working in a sitting position and had not previously performed intensive training (which could disturb the feeling of the indoor microclimate). Moreover, all tests were carried out with one device, at the same times of the day, in the same building, so as to maintain the reliability of the tests performed. Every effort was made to ensure that the received questionnaires with subjective assessments of people were the most objective analysis of the obtained results.

In each test room, the Testo meter was placed in the centre of the room, at the height of the seated persons. The stabilization period of the parameters was about 15 minutes. After this time, the parameters were recorded in the research $\log$ and on the meter itself. Meanwhile, study volunteers focused on completing questionnaires on the assessment of lighting and their learning productivity. Again, after 15 minutes, the questionnaires were collected and submitted for analysis. The tests were carried out in 13 classrooms, at different times of the year, from November 2020 to July 2021. 164 participants took part in the study, where the participation of women in the study was $35.98 \%$, and men $-64.02 \%$.

\section{Results and discussion}

The results obtained from the meter determined that the temperature in the 13 rooms was 19.3 to $25.2\left[{ }^{\circ} \mathrm{C}\right.$ ], the amount of carbon dioxide was from 438 to 1255 [ppm], for the light intensity the range was from 49.8 to 898 [lx]. The respondents were to determine whether the light in the room at a given moment is 'too strong' $(+1)$, 'appropriate' (0) and 'too weak' (-1). Figure 4 shows the overall assessment of the light intensity in the studied classrooms based on the responses of the respondents (Light assessment vote - LAV).

The overall lighting rating was considered appropriate (0) according to $82.32 \%$ of the respondents. On the other hand, $10.98 \%$ of people considered the lighting as 'too weak' (-1) and $6.71 \%$ of people stated that the light in the rooms was 'too strong' (1). Analysing the above results, it can be concluded that, according to the overall assessment, the students confirm that the lighting is appropriate and that the building meets their expectations of an intelligent building.

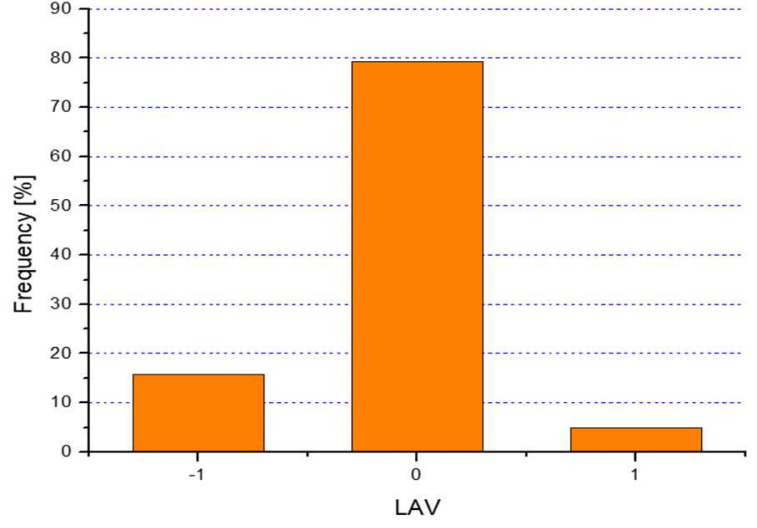

Fig. 4. Assessment of light intensity based on the analysis of students' answers: : -1 - too weak; 0 - suitable; 1 - too strong.

The light intensity and the average lighting assessment vote (LAV-a) according to the respondents from 13 rooms are shown in Figure 5.

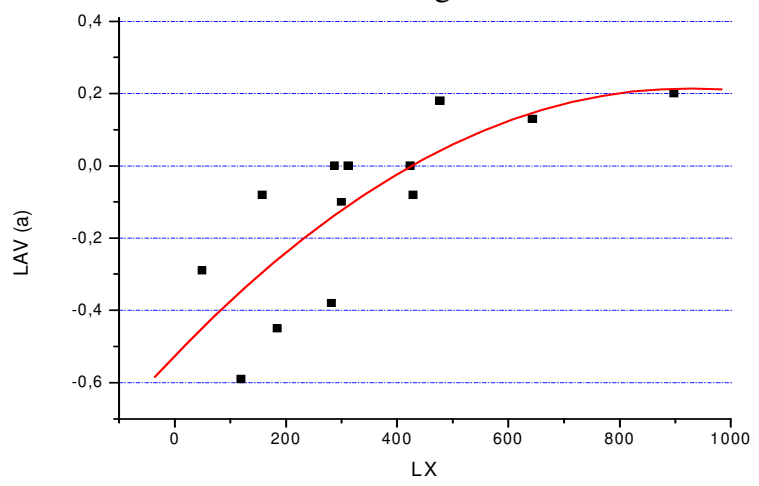

Fig. 5. The light intensity and the average lighting assessment vote (LAV -a).

When analyzing Figure 5, according to the average people's assessment of lighting, it was declared that the light in the lecture halls was too weak. It concerned the average grade below 430 [1x], which resulted in the lack of satisfaction with lighting. The highest satisfaction with the prevailing conditions was in the eighth room, where the intensity was 898 [1x]. On the other hand, the lowest satisfaction was found in room 10 , where the intensity was $120[\mathrm{~lx}]$. The confirmation of this analysis is the line which starts to stabilize from the value of 550 [lx] to its maximum at the value of 898 [1x]. The standard stipulates that the minimum value for such rooms should be 300 or more.

However, based on the research, this range should be increased to a minimum of 430 [1x], so that people feel good indoors, because they definitely prefer stronger light. Apart from assessing the light intensity in the classrooms, the students were also to present their mood in questionnaires. The answers that could be marked were very good $(+2)$, good $(+1)$, indifferent $(0)$, bad $(-1)$ and very bad $(-2)$. Therefore, the average rating of lighting (LAV-a) according to the respondents was compared, based on the data in Figure 5, and the average of the response describing well-being. This is to check whether the intensity of lighting can improve or worsen your well-being. The average rating of lighting (LAV-a) from 13 rooms and the average voices describing wellbeing are presented in Figure 6. 


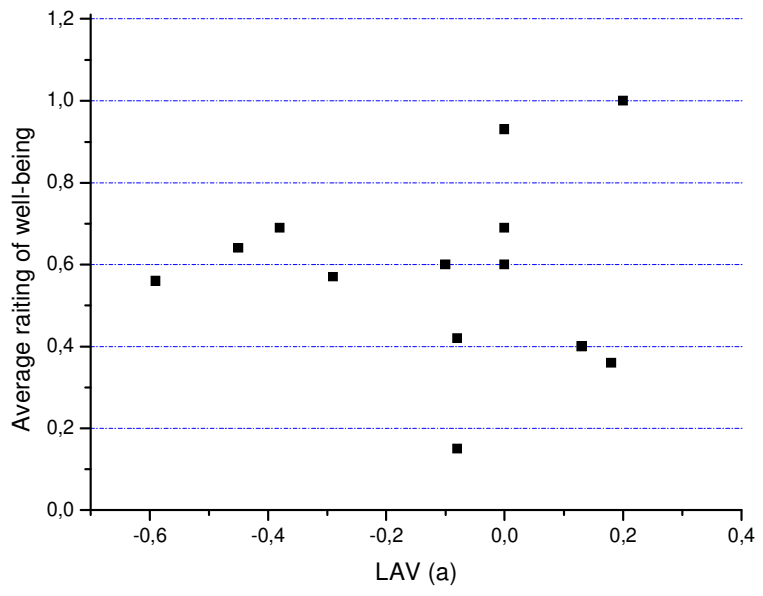

Fig. 6. The average lighting rating and average well-being rating for each lecture hall.

The obtained averages of the respondents' answers showed that the lighting did not improve or worsen the well-being of the respondents. If it were to make you feel better, the averages would be high on the chart.

The next part of the analysis was to make an assessment regarding the subjective productivity of the students. Figure 7 presents the test results for all the rooms.

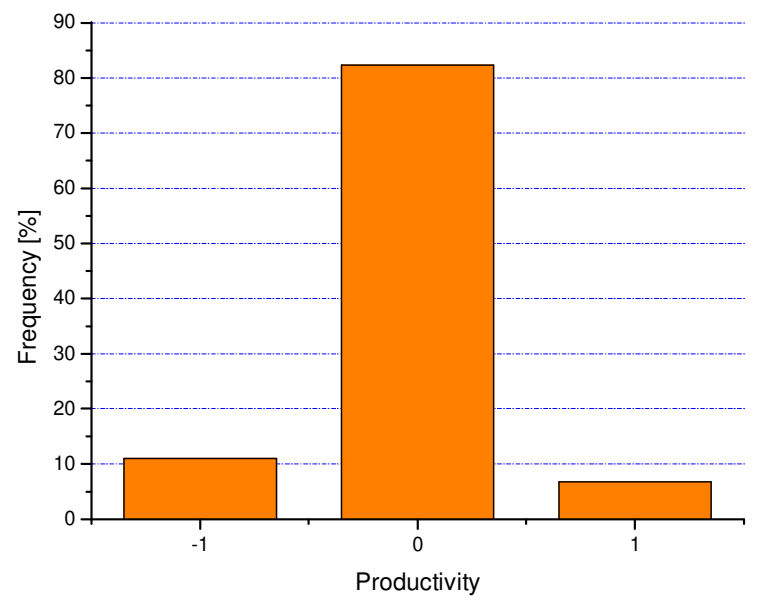

Fig. 7. The frequency of responses given by respondents regarding productivity: -1 - Weak (worse than usual), 0 Normal (the same as usual), 1 - High (better than usual).

The most frequently given productivity response was "Normal" and it accounted for $82.32 \%$ of all responses. The second answer given was "Weak" and amounted to $10.98 \%$, while the least frequently chosen answer was "High" $(6.71 \%)$. It is worth noting that the thermal sensations of the respondents depend on many factors, including temperature, air velocity, and even clothing. It is also worth checking whether lighting and temperature have an impact on the productivity of people in the tested rooms - this is shown in Figure 8.

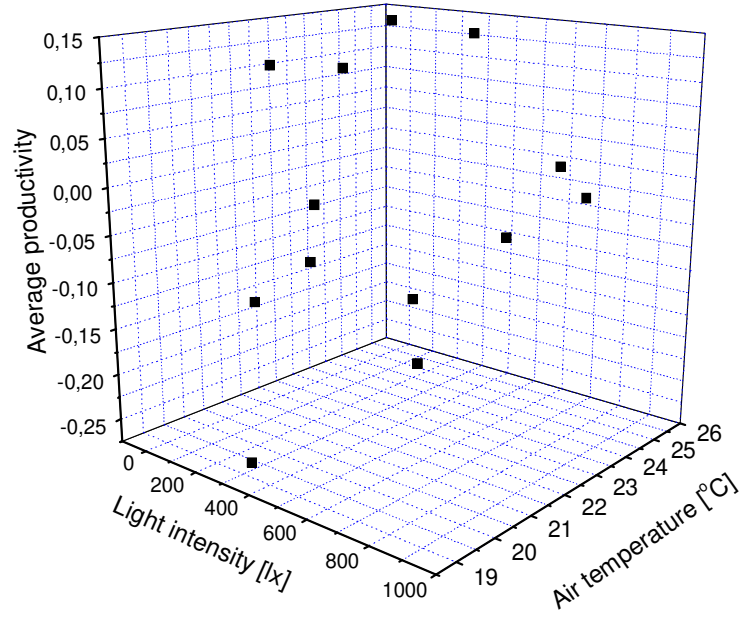

Fig. 8. Graph of light intensity [lx], average productivity and air temperature.

When analysing user performance studies, it can be noticed that the light intensity and temperature might not have a significant impact on the products (on the ability to learn) - in the analysed range of changes of these parameters. However, the best solution is to conduct more tests and check on a larger number of people tested whether the lighting and temperature actually have no significant impact on increasing or reducing the efficiency of work and learning. The next figure (Fig. 9) shows the average value of well-being and its relationship with productivity for 13 groups of students.

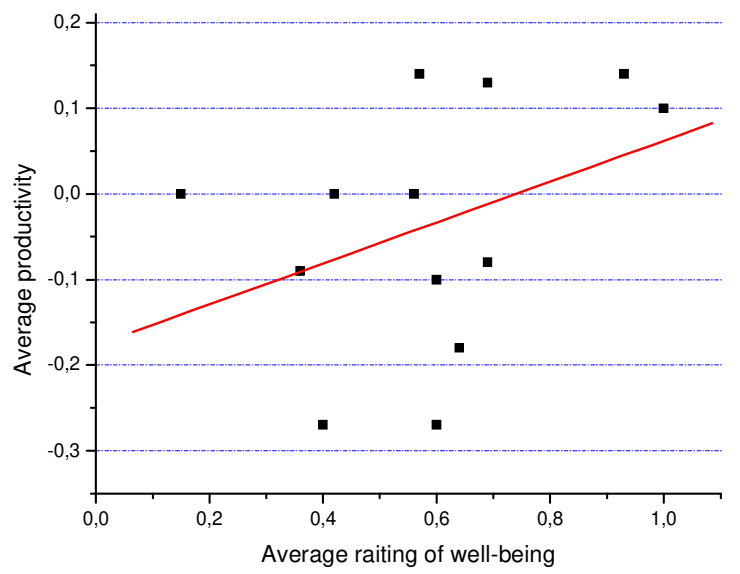

Fig. 9. Graph of average rating of well-being and average productivity.

By analysing this chart in terms of the overall assessment and the average productivity value of the rooms tested. From the chart, one can see that students who feel better indoors have better productivity. The value of the matching factor $\mathrm{R}^{2}$ is 0.1437 . It means that the relationship is not very strong.

\section{Conclusions}


The above analysis showed a small effect of the quality of the light intensity on the well-being and productivity of the students. The results obtained from the tests are a satisfactory light intensity of 430 [1x] for a classroom, where the standard according to EN 12464-1: 2012 is $300[1 \mathrm{x}]$. The respondents also confirmed in their responses that they feel better and show greater productivity in stronger lighting. The readings in figure 6 clearly illustrate the situation for each lecture hall, i.e. the respondents do not feel as satisfied with the lower light. The number of tests performed for various groups of people allows us to conclude that people staying in rooms more and more often consider lighting as a factor influencing their well-being. Therefore, in the future, it is worth considering the fact of changing the light intensity to a higher value, at least the same as obtained in the study. In general, the lighting in the examined intelligent building was selected very well, according to $80 \%$ of the respondents, and the productivity was considered normal by $82.32 \%$. Further analysis did not show that lighting and temperature had an influence on the increase or decrease of knowledge absorption (productivity) in the analyzed range of changes of these parameters. In order to obtain additional conclusions, the scope of the research should be extended to include a larger group of respondents.

\section{References}

1. Regulation of the Minister of Labour and Social Policy of 26 September 1997 on general rules of safety and hygiene at work, Journal of Laws of 2003. No. 169, item 1650 as amended. - par. 26 (2)

2. EN 12464-1:2012, Light and lighting - Lighting of workplaces - Part 1: Indoor workplaces (2012)

3. A. M. Idkhan, F. R. Baharuddin,, Int. J. Environ. Eng. Educ., vol. 1, no. 2 (2019). https://doi.org/10.5281/zenodo.3477838

4. L. Bellia, F. R. d'A. Alfano, F. Fragliasso, B. I. Palella, G. Riccio, En. \& Build., 231 (2021). https://doi.org/10.1016/j.enbuild.2020.110570

5. J. Kussmaul, K. Peri, M. Boyd, Aus. J. of Adv. Nur., 36, 4 (2019). ISSN:0813-0531

6. A. Lipczyńska, S. Schiavon, L.T. Graham, BaE 135, 202-212 (2018). https://doi.org/10.1016/j.buildenv.2018.03.013

7. T. Akimoto, S. Tanabe, T. Yanai, M. Sasaki, BaE 45, 45-50 (2010). https://doi.org/10.1016/j.buildenv.2009.06.022

8. Y. He, W. Chen, Z. Wang, H. Zhang, E\&B 194, 140-162 (2019). https://doi.org/10.1016/j.enbuild.2019.04.015

9. O. Göçer, Ch. Candido, L. Thomas, K. Göçer, Buildings 9, 199 (2019). https://doi.org/10.3390/buildings909019

10. Piotrowski J.Zb., Orman Ł.J., Lucas X., Zender Świercz E., Telejko M., Koruba D., Tests of thermal resistance of simulated walls with the reflective insulation, Proc. of Int. Conf. "Experimental Fluid Mechanics 2013”, Czech
Republic, EPJ Web of Conferences, 67, 02095, 2014.

https://doi.org/10.1051/epjconf/20146702095 